\title{
Stitching Triple Cation Perovskite by a Mixed Anti-Solvent Process for High Performance Perovskite Solar Cells
}

Yafei Wang ${ }^{\mathrm{a}}$, Jiang $\mathrm{Wu}^{\mathrm{b}}$, Peng Zhang ${ }^{\mathrm{a}}$, Detao Liu ${ }^{\mathrm{a}}$, Ting Zhang ${ }^{\mathrm{a}}$, Long Ji ${ }^{\mathrm{a}}$, Xiangling Gu ${ }^{\mathrm{a}}$, Zhi David Chen ${ }^{\mathrm{a}, \mathrm{c}^{*}}$, and Shibin $\mathrm{Li}^{\mathrm{a}}{ }^{*}$

${ }^{a}$ State Key Laboratory of Electronic Thin Films and Integrated Devices, and School of Optoelectronic Information, University of Electronic Science and Technology of China (UESTC), Chengdu, Sichuan 610054, China

${ }^{\mathrm{b}}$ Department of Electronic and Electrical Engineering, University College London, Torrington Place, London WC1E7JE, United Kingdom

${ }^{\mathrm{c}}$ Department of Electrical \& Computer Engineering, and Center for Nanoscale Science \& Engineering, University of Kentucky, Lexington, Kentucky 40506, USA

*Corresponding authors: shibinli@ uestc.edu.cn, zhichen@engr.uky.edu

\section{Abstract}

With the rapid development of organic-inorganic lead halide perovskite photovoltaics, increasingly more attentions are paid to explore the growth mechanism and precisely control the quality of perovskite films. In this study, we propose a "stitching effect" to fabricate high quality perovskite films by using chlorobenzene (CB) as an anti-solvent and isopropyl alcohol (IPA) as an additive into this anti-solvent. Because of the existence of IPA, CB can be efficiently released from the gaps of perovskite precursors and the perovskite film formation can be slightly modified in a controlled manner. More homogeneous surface morphology and larger grain size of perovskite films were achieved via this process. The reduced grain boundaries ensure low surface defect density and good carrier transport in the perovskite layer. Meanwhile, we also performed the Fourier transform infrared (FTIR) spectroscopy to investigate the film growth mechanism of unannealed and annealed perovskite films. Solar cells fabricated 
by using the "stitching effect" exhibited a best efficiency of $19.2 \%$. Our results show that solvent and solvent additives dramatically influenced the formation and crystallization processes for perovskite materials due to their different coordination and extraction capabilities. This method presents a new path towards controlling the growth and morphology of perovskite films.

\section{Introduction}

Organic-inorganic hybrid halide perovskite has recently emerged as one of the most promising materials for the low-cost third generation photovoltaic technology. Over the past few years, the power conversion efficiency (PCE) of perovskite solar cells (PSCs) has rapidly increased from 3.8\% to more than 22.1\%.[1-2] During this process, most works focus on deposition methods, interface engineering, hysteresis in the current-voltage curves of PSCs and the application of new functional materials.[3-12] In order to make it more conducive to practical application, the degradation mechanism of perovskite in air and the fabrication process of larger sized devices are investigated by a lot of research groups. [13-17] As a result, precisely controlling the growth of perovskite crystals has also become an interesting topic to explore the fundamental properties and growth dynamics of high quality perovskite films for efficient solar cells.

A lot of efforts has been devoted to improve the morphology, coverage, grain size of perovskite films, which play an important role in the performance of PSCs. [18-20] It is well known that grain size is a key factor related to the diffusion length of carriers, the rate of carrier recombination and charge generation.[19] To well control the fabrication of dense and uniform perovskite films with large grain size is challenging 
and meaningful. Compared with other deposition methods (such as vapor deposition, vapor-assisted deposition, atomic layer deposition etc.), solution deposition is a simple and low-cost way to fabricate high efficiency PSCs. [5-6,21-31] Several researches have been reported in obtaining high quality perovskite films based on growth engineering, solvent engineering and so on. In 2016, M. Dar and his coworkers studied the impact of chloride on the conversion of lead halide into $\mathrm{CH}_{3} \mathrm{NH}_{3} \mathrm{PbI}_{3}$.[21] The surface coverage of the perovskite film was effectively improved and material defects were reduced by adding $2 \%$ chloride in perovskite precursors. In order to optimize perovskite film quality, solvent engineering, especially mixed-solvent process, was widely investigated.[5-6] Various solvents were employed in the dissolved solution of perovskite precursors, solvent annealing, the solution of iodide methylammonium (MAI) and so on. Huang's group firstly proposed the solvent annealing on organicinorganic perovskite materials in 2014.[22] DMF was used in the annealing of perovskite which successfully enhanced the grain size of $\mathrm{CH}_{3} \mathrm{NH}_{3} \mathrm{PbI}_{3}$. Unlike DMF, DMSO molecules have strong coordination effect with $\mathrm{Pb}^{2+}$ so that DMSO was widely used to retard the crystallization of $\mathrm{PbI}_{2}$ and improve the quality of perovskite films.[5] Using the DMSO solvent annealing process, a mesoporous structure of $\mathrm{PbI}_{2}$ and large grain size of $\mathrm{CH}_{3} \mathrm{NH}_{3} \mathrm{PbI}_{3}$ were achieved in our precious studies. In addition to strongly polar solvents, some weakly polar solvents (ethanol, acetonitrile, isopropanol, etc.) were also investigated. Li et al. introduced acetonitrile solvent to successfully mediate the nucleation and grain growth of perovskite films.[23] $\mathrm{Wu}$ et al. and Sun et al., respectively, employed DMF/CB and DMF/IPA solvent annealing to obtained smooth 
and dense surface morphology of $\mathrm{CH}_{3} \mathrm{NH}_{3} \mathrm{PbI}_{3}$.[24-25] Alcohol-vapor annealing treatment on $\mathrm{CH}_{3} \mathrm{NH}_{3} \mathrm{PbI}_{3}$ was reported by Liu et al., aiming to improve the crystal growth and increase the grain size of perovskite crystals. [3] Actually, such low-polar solvents have the weak coordination ability with perovskite precursors which could play an important role in the growth of perovskite crystals. Note that, weak coordination ability was brought up here because of the poor solubility of lead ions and weak electron donating ability. Seok and his group reported a new one-step deposition method using a mixed solution of GBL and DMSO as the solvent of perovskite precursors and toluene was employed as the anti-solvent in this one-step procedure to achieve homogeneous interface morphology of perovskite.[26] After that, Park and his group used diethyl ether as the anti-solvent to remove DMF solvent molecules in their experiment.[27] They made highly reproducible $\mathrm{CH}_{3} \mathrm{NH}_{3} \mathrm{~Pb}_{3}$ solar cells with an average PCE of $18.3 \%$ and the best efficiency of $19.7 \%$. Since then, anti-solvent deposition method has become a common way to fabricate high quality perovskite films and efficient PSCs. However, few works have investigated the effects of different anti-solvents in the nucleation kinetics of perovskite and the influence on triple cation perovskite crystal growth. It is thus very important and meaningful to reveal the influence of anti-solvent on perovskite crystal growth and film formation.

Precisely controlling growth of perovskite nano-films and understanding the mechanism of grain formation are always required for fabrication of high quality perovskite materials and their long-term application in optoelectronics. There are very few reports on the function and effect of weak coordination solvent in the anti-solvent 
process.[23, 32] Especially for multi-ion perovskite materials, the growth control of perovskite films are important. Weak coordination solvents could effectively adjust the balance between the reduction of grain boundaries and the modification of films based on their low boiling point, good volatility and low solubility of perovskite relative to strong polar solvents. Here the weak coordination solvents are referred as solvent with poor solubility of lead ions, weak interaction between solvent molecular and $\mathrm{Pb} 2+$, and weak electron donating ability.. Normally, chlorobenzene (CB) is often used as the antisolvent for fabricating perovskite films. Chlorobenzene has a poor volatility and an insoluble property of perovskite and could remain in gaps of the perovskite film and cause cracks in the anti-solvent process. It is helpful and desired to introduce weak coordination solvent in the formation process of triple cations perovskite films. On the one hand, some weak coordination solvent could remove the residual CB quickly, which reduces the number of grain boundaries and enhances the grain size of perovskite films. However, weak coordination solvent could modify the surface via its low solubility of perovskite and perovskite precursors.

In this paper, we employed some weakly polar solvents (isopropanol, acetone) in the anti-solvent process designed to control the surface morphology and explore the growth mechanism of triple cation perovskite films. Here, we found a "stitching effect" of IPA/CB mixed anti-solvent in washing processes. This effect can be used to achieve large grain sizes of perovskite films by addition a proper amount of IPA in CB. Compared to $\mathrm{CB}$, isopropyl alcohol offers a higher solubility for perovskite precursor. IPA molecules play an important role in stitching cesium-containing triple cation 
perovskite grains so that more homogeneous morphology and lower defect density of perovskite films were achieved via this process. The best solar cell exhibited a stabilized PCE of 19.2\%. We believed the stitching effect of mixed anti-solvent washing process can be very useful for understanding the formation mechanism of perovskite and fabricating high quality large-scale perovskite films.

\section{Results and Discussion}

Cesium (Cs) has been studied in detail by Grätzel and his co-workers in the triple cation perovskite compositions.[33] $\mathrm{Cs}_{5} \mathrm{FA}_{79} \mathrm{MA}_{16} \mathrm{PbI}_{2.5} \mathrm{Br}_{0.5}$ perovskite film exhibited improved stablility and had the best performance. We employed this perovskite material in our study. Figure 1(a) exhibits the fabrication schematic of triple cation perovskite films prepared by an anti-solvent process. The $\mathrm{Cs}_{5} \mathrm{FA}_{79} \mathrm{MA}_{16} \mathrm{PbI}_{2.5} \mathrm{Br}_{0.5}$ precursor was stirred more than 6 hours to ensure sufficient and uniform dissolution. Then this solution was spin-coated on a $\mathrm{TiO}_{2}$ substrate, and different anti-solvents were poured on films with high speed rotation. In this process, we investigated eight different ratios between CB and IPA (1:0, 1:0.01, 1:0.02, 1:0.04, 1:0.06, 1:0.08, 1:0.1, 0:1) to control the interface morphology and grain size of perovskite films. The film was annealed at $110{ }^{\circ} \mathrm{C}$ for more than $1 \mathrm{~h}$. Such a long stirring time and high annealing temperature were employed to ensure the complete reaction between FAI, MABr, $\mathrm{PbI}_{2}, \mathrm{PbBr}_{2}$ and $\mathrm{CsI}$. We also used acetone as an additive solvent for CB. Although acetone is a strong solvent to halide perovskite, it has a much lower solubility of lead iodide and a much weaker coordination with lead ions than DMSO, DMF, GBL etc., and therefore acetone is also used here as one kind of weak coordination solvent for comparison. The J-V curve of 
the PSC based on mixed solvent of acetone and CB washing process is showed in supplementary materials (FigureS1). The UV-visible (range from $300 \mathrm{~nm}$ to $1000 \mathrm{~nm}$ ) absorption spectra of perovskite films prepared with different CB/IPA ratios were measured and shown in Figure 1(b). There are similar absorption spectra of perovskite films and based lines. However, it is also obvious that the absorption of perovskite films obtained via the mixed anti-solvent processes is slightly larger at $\sim 760 \mathrm{~nm}$ than that of the perovskite films prepared using pure IPA or $\mathrm{CB}$ as the washing solvent. This illustrates the IPA/CB mixed anti-solvent improves the optical absorption of perovskite films. In order to study this optical absorption in more details, we intercept UV-Vis absorption spectrum from $700 \mathrm{~nm}$ to $800 \mathrm{~nm}$ in Figure1(c). Fig.1(c) shows three absorption steep slopes at $760 \mathrm{~nm}$ for perovskite films fabricated by the anti-solvent ratios of $\mathrm{CB}$ : $\mathrm{IPA}=1: 0,1: 0.06$, and 0:1 respectively. With $6 \%$ percent IPA addition, $\mathrm{Cs}_{5} \mathrm{FA}_{79} \mathrm{MA}_{16} \mathrm{PbI}_{2.5} \mathrm{Br}_{0.5}$ film achieved the highest absorption at $760 \mathrm{~nm}$. IPA (polarity= 4.3) is a polar solvent with a low boiling point and $\mathrm{CB}$ (polarity=2.7) is a nonpolar solvent. It is well known that strong polar solvents such as DMF (polarity=6.4), DMSO (polarity $=7.2$ ) etc. are usually used to dissolve perovskites. Therefore perovskite precursors also have a very weak solubility in IPA. The addition of IPA actually resulted in a surface modification of perovskite films. Meanwhile, because of the lower boiling point, IPA also can take CB away from the surface efficiently, which enhances the perovskite grain size and crystallinity, and thereby improves the optical absorption of perovskite films. It's worth noting that the film with pure IPA washing process also exhibits an obviously absorption slope at $760 \mathrm{~nm}$, which indicates the perovskite was 
formed in this process. However, the lower absorption of perovskite should be owing to the different anti-solvent extraction properties between IPA and CB. Too much isopropanol could dissolve the perovskite and rearrange the films. All in all, with the ratio of $\mathrm{CB}$ : $\mathrm{IPA}=1: 0.06$, the highest optical absorption of the perovskite film was achieved. This ratio should be the best proportion for the mixed anti-solvent and "stitching effect". The following J-V curves (Figure 1(e)) and parameter statistics of PSCs (Figure 2(a)-(d)) also confirm this conclusion.

Figure 1(d) presents the XRD spectra of perovskite films made by the anti-solvent ratios of $\mathrm{CB}$ : IPA=1:0, 1:0.06, 0:1. The XRD patterns with perovskite peaks at $14.16^{\circ}$, $19.8^{\circ}, 24.4^{\circ}, 28.1^{\circ}, 31.55^{\circ}, 34.67^{\circ}, 40.17^{\circ}, 42.7^{\circ}, 49.68^{\circ}$ and $51.91^{\circ}$, corresponding to the (111), (012), (003), (222), (123), (114), (024), (015), (006) and (135) planes, respectively, were observed in the figure. The perovskite peaks of the (111), (003), (123) and (015) are higher and sharper for the film prepared by the mixed anti-solvent process. Through calculating and fitting, the full width at half maximum (FWHM) of the (111) diffraction peak has been obtained. The FWHM of (111) peak for the sample prepared with mixed anti-solvent is 0.294 , which is lower than that $(0.347)$ of the sample made with $\mathrm{CB}$ washing process. This suggests that suitable isopropyl alcohol anti-solvent additive could enhance the crystallinity of triple cation perovskite. Meanwhile, there is no XRD peak of $\delta$-perovskite at $11.6^{\circ}$ for the perovskite treated by IPA and mixed solvent washing, indicating that IPA is conducive to remove the $\delta$ phase of perovskite. A weak diffraction pattern of $\mathrm{PbI}_{2}$ appeared when IPA was employed. This peak of $\mathrm{PbI}_{2}$ should be ascribed to the different solubility of lead iodide and FA compounds in 
isopropanol. The XRD measurement of perovskite prepared with pure IPA washing is consistent with this result. A much stronger diffraction peak of the $\mathrm{PbI}_{2}$ (001) plane at $12.4^{\circ}$ is shown in the XRD curve of perovskite based on pure IPA washing process. Although there are a lot of discussions about the function of residual $\mathrm{PbI}_{2}$, it is hard to tell the exact impact of such little residual $\mathrm{PbI}_{2}$ on this mixed anti-solvent process for triple cation perovskite formation. It is very interesting to notice that the perovskite film fabricated with pure IPA washing also has much stronger diffraction peaks of the (003) and (006) planes at $24.42^{\circ}$ and $49.68^{\circ}$, which shows another growth mode of perovskite films. The (003) and (006) planes are all parallel to the substrate. Isopropanol washing induced the parallel growth of perovskite and ensured a good crystallinity. Because of this, we can observe the perovskite (003) peak becomes slightly stronger and sharper when treated with the mixed anti-solvent than that prepared by the pure CB. Combined with the influence of chlorobenzene and isopropanol, the sample made with the mixed solvent washing has shown better UV-Vis absorption and film crystallinity.

The current density-voltage $(\mathrm{J}-\mathrm{V})$ curves of devices processed in different washing solvents with various mixing ratios between chlorobenzene and isopropanol are shown in Figure 1(e). The sample fabricated with the anti-solvent ratio of CB: IPA=1: 0.06 exhibits the best conversion efficiency which is $17.8 \%$. This result is consistent with the previous UV-Vis absorption and XRD analyses. Actually, the sample via pure chlorobenzene washing process exhibits a PCE of $16.1 \%$, not the lowest one among these devices. There is a tendency for the PCE to drop first and then rise again with increasing amount of IPA. Because of the difference (boiling point, density, solubility, 
polarity etc.) between the CB and IPA, very little IPA couldn't evenly modify the films and affect CB. On the other hand, too much IPA would reduce the UV-Vis absorption of perovskite and change the growth mode of perovskite. Therefore, one needs to strike a delicate balance between the ratio of $\mathrm{CB}$ and IPA in order to form high quality perovskite films; in this study, the ratio $\mathrm{CB}$ : IPA=1: 0.06 was found to be the optimum proportion for preparation of high quality triple cation perovskite films. The PCE of the sample based on pure IPA washing process is exhibited in the supporting information.

Figure 2(a)-(d) show parameter $\left(\mathrm{J}_{\mathrm{SC}}, \mathrm{V}_{\mathrm{OC}}, \mathrm{FF}\right.$ and PCE) statistics of devices fabricated using various anti-solvents with different $\mathrm{CB} / \mathrm{IPA}$ ratios. In addition to $\mathrm{J}_{\mathrm{SC}}$, it is clearly that $\mathrm{V}_{\mathrm{OC}}, \mathrm{FF}$ and PCE all exhibit the similar trend with the result illustrated in Figure 1(e). VOC and FF reflect the junction properties of PSCs.[34] Higher $V_{O C}$ and $\mathrm{FF}$, and hence the enhancement of the power conversion efficiency (PCE), are due to the enhancement of the quality of perovskite films. However, as shown in Figure 2(a), the current density $\left(\mathrm{J}_{\mathrm{SC}}\right)$ has been significantly improved along with adding IPA in antisolvent. This result illustrates mixed washing solvent could reduce the recombination via "stitching" grains. Furthermore, the solar cells show good reproducibility of parameters, including $\mathrm{J}_{\mathrm{SC}}, \mathrm{V}_{\mathrm{OC}}, \mathrm{FF}$ and PCE.

To probe the "stitching effect" of the IPA and CB mixed washing solvent directly, we measured the surface morphology of the perovskite films by SEM and the SEM images are shown in Figure 3(a)-(c). Perovskite films fabricated by three CB: IPA ratios (1:0, 1:0.06, 0:1) were presented here. All three processes result in dense surface morphologies of perovskite films. It is particularly interesting to see that different grain 
sizes were achieved through these three anti-solvents. The grain size statistics of perovskite films are also shown in Figure 3(d) (calculated by Nano Measurement software). Unlike the strong binding ability of DMSO with $\mathrm{Pb}^{2+}$, IPA just has a weak coordination with triple perovskite precursors and chlorobenzene. Further analysis of washing process is as follows: isopropanol dissolved little perovskite and perovskite precursor due to their low solubility in IPA, then IPA also released more quickly than $\mathrm{CB}$ when films were washed by anti-solvent and annealed on the hot plate. Because of these two reasons, grain boundaries of perovskite were reduced by stitching small grains and the surface morphology of perovskite became smoother. Through this "stitching effect", lager perovskite grains exhibit lower recombination and better junction properties as shown in Figure 3(e) and (f). From these two figures, the integrated steady photoluminescence (integrated PL) and plots of $-d V / d J$ versus $\left(\mathrm{J}_{\mathrm{SC}}\right.$ $\mathrm{J})^{-1}$ (including the linear fitting curves) are studied to investigate the recombination and heterojunction properties of solar cells. The samples contain compact $\mathrm{TiO}_{2}$, mesoporous $\mathrm{TiO}_{2}$ and perovskite layers. From Figure 3(e), where the sample prepared with mixed solvent (CB: IPA= 1:0.06) achieved the highest integrated PL intensity. The intensity of steady PL are always associate with factors: nonradiative recombination and charge transfer at interface.[28,35-38] According to our device structure, the higher steady PL intensity means lower nonradiative recombination. Stitching effect of mixed antisolvent results in high quality perovskite film with lower trap states. The PL spectrums are shown in Figure S8. We can see that intensities of integrated steady PL spectra also obey the trend of the $\mathrm{V}_{\text {OC, }}$ FF and PCE statistics. Figure S11 shows the cross-sectional 
SEM images of the perovskite films prepared by the CB, mixed anti-solvent (CB: IPA=1:0.06) and IPA washing processes. The achieved capping layer thicknesses show marginal difference and are $401 \mathrm{~nm}(\mathrm{CB}), 392 \mathrm{~nm}$ (mixed solvent) and 433 (IPA) nm, respectively. To further investigate the photovoltaic characteristics, Figure 3(f) shows the plots of $-\mathrm{dV} / \mathrm{dJ}$ versus $\left(\mathrm{J}_{\mathrm{SC}}-\mathrm{J}\right)^{-1}$ and the linear fitting curves to calculate the ideal factor of the heterojunction. The formula is expressed as:

$$
-\frac{d V}{d J}=\frac{N K_{B} T}{e}\left(J_{S C}-J\right)^{-1}+R_{S}
$$

Where $R_{S}$ is the series resistance, $\mathrm{J}_{\mathrm{SC}}$ is the short circuit current density, $\mathrm{J}$ is the current density flowing through the external load, $\mathrm{N}$ is the ideality factor of a heterojunction, $\mathrm{K}_{\mathrm{B}}$ is the Boltzmann constant, $\mathrm{T}$ is the absolute temperature, $\mathrm{e}$ is the elementary charge, and V is the DC bias voltage that applied to the cell. It is obviously that the device made through mixed solvent $(\mathrm{CB}$ : IPA=1:0.06) agrees best with this heterojunction solar cell analysis. In this case, the ideality factor is 1.64. Meanwhile, the calculation ranges from 0.03 to 0.06 (range=0.03) on the $\mathrm{x}$-axis. Compared with the previous report, this range is similar with that reported by Meng's group (which ranges from 0.02 to 0.05 ). [34] For a well-behaved heterojunction solar cell, $\mathrm{N}$ is always between 1.3 and 2. For the samples based on other anti-solvent process of ratio CB: $\mathrm{IPA}=1: 0,1: 0.01,1: 0.02,1: 0.04,1: 0.08,1: 0.1, \mathrm{~N}$ values of $2.35,2.95,3.12,2.54,1.76$ and 2.11 are achieved respectively. The improvement of the junction ability should be owing to the larger grain size and better quality of perovskite films. This result is consistent with our SEM, XRD and PL measurements. Again, the successful fabrication of high quality perovskite films by using the "stitching effect" of mixed solvent (CB: 
IPA=1:0.06) process is confirmed. Figure 3(g) shows the cross-sectional SEM image of a complete sample fabricated by using the mixed anti-solvent (CB: IPA=1:0.06) process. The device was fabricated with the structure as follows: fluorine doped tin oxide (FTO)/compact $\mathrm{TiO} 2 /$ mesoporous $\mathrm{TiO} 2 /$ triple cation perovskite /spiro-OMeTAD $(\mathrm{HTM}) / \mathrm{Au}$ contact. The thickness of the perovskite layer is about $417 \mathrm{~nm}$. And we can clearly observe that the perovskite capping layer has high quality and good crystallization.

In order to further study the surface morphology and roughness of triple cation perovskite films based on $\mathrm{CB}$, mixed solvent(CB:IPA=1:0.06) and IPA, respectively, AFM images are shown in Figure 4(a)-(c). Tapping mode was used in this measurement. It can be seen that there is a rough surface with large undulating grains of perovskite in Figure 4(a). Pure CB washing induced an uneven surface with the root mean square roughness (RMS) of $62 \mathrm{~nm}$. Furthermore, there are some unclear image area in Figure 4(a). This is because the surface is very rough while AFM measurement is usually employed to study relatively smooth materials. [39-41] When the mixed solvent was used in the fabrication of perovskite, the grains became larger and connected. The RMS decreases to $53 \mathrm{~nm}$ compared to that based on pure $\mathrm{CB}$ washing process. The surface morphology of perovskite prepared in pure IPA washing is smoother than that of the first two films. It shows a RMS of $43 \mathrm{~nm}$, which is the lowest in these three samples. Height distribution of perovskite films are shown in Figure 4(d)-(f), which correspond to Figure 4(a)-(c), respectively. With the increase in the proportion of isopropanol in the mixed solvent, the height distribution is even more uniform and the intermediate 
threshold is lower. The intermediate height threshold decreased from $179 \mathrm{~nm}$ to $112 \mathrm{~nm}$ when using IPA instead of $\mathrm{CB}$ as anti-solvent. In short, AFM measurements are consistent with the previous result that triple cation perovskite with less boundaries ascribed to the modified surface morphology via the "stitching effect".

It is very necessary and interesting to reveal the mechanism of the "stitching effect" in the mixed solvent washing procedure. A schematic film growth process is shown in Figure 5(a). During normal CB washing process, CB quickly extracts DMF and DMSO from perovskite films as an anti-solvent. Chlorobenzene has a high boiling point of $132.2{ }^{\circ} \mathrm{C}$ and a bad volatility. At the same time, perovskite and perovskite precursors are insoluble in chlorobenzene. So, after CB extracting the solvents from the perovskite film in this washing process, some chlorobenzene remains on the moist perovskite film. These residual $\mathrm{CB}$ won't leave until the film begin to heat at $100{ }^{\circ} \mathrm{C}$. Then an uneven film with many boundaries and a roughness surface is formed. When IPA is added into the anti-solvent, IPA removes the residual CB quickly through its much lower boiling point and better volatility. So some boundaries are disappeared because of this "stitching effect". Meanwhile, IPA has a relatively stronger polarity than CB since IPA can dissolve a small amount of perovskite and perovskite precursors. However, this dissolution property is much lower than DMF, DMSO etc. Therefore, this influence of IPA is marginal.

To gain further insights into this "stitching effect" of mixed anti-solvent process, we perform Fourier transform infrared spectrometer (FTIR) measurements to analyze the interaction process in this film growth procedure. Here, we studied both annealed 
perovskite films and unannealed perovskite films. The FTIR measurement used transmission mode in the range of $4000-400 \mathrm{~cm}^{-1}$. Three cases include CB washing, IPA washing and mixed anti-solvent washing $(\mathrm{CB}: \mathrm{IPA}=1: 0.06)$ were considered in our experiment. Figure 5(b) shows the FTIR absorption spectra of annealed perovskite films. All the samples show a low transmission and the similar shape in the long wave number range from $3000 \mathrm{~cm}^{-1}$ to $4000 \mathrm{~cm}^{-1}$. Such high baselines suggest strong light scattering and light absorption. However, the transmission between $3500 \mathrm{~nm}^{-1}$ and 3200 $\mathrm{nm}^{-1}$ represents the N-H stretch in FA cation.[42] Because of the high baseline, the N$\mathrm{H}$ peaks seem very weak. The N-H stretch is more obvious in the FTIR absorption spectra of unannealed perovskite films, as shown in Figure 5(c). For these unannealed films, there is a much stronger transmission of the perovskite based on the mixed antisolvent process. Some weak peaks of N-H stretch are shown in curves in the range from $3500 \mathrm{~nm}^{-1}$ to $3200 \mathrm{~nm}^{-1}$. The peak of C-OH (belongs to IPA) shown between $3700 \mathrm{~nm}^{-}$ ${ }^{1}$ and $3500 \mathrm{~nm}^{-1}$ is more obvious for the mixed anti-solvent case. Actually, we are more interested in the wavenumber between $1650 \mathrm{~nm}^{-1}$ to $1550 \mathrm{~nm}^{-1}$ which represents the $\mathrm{C}=\mathrm{C}$ vibration only belongs to chlorobenzene. In Figure $5(\mathrm{~b}), \mathrm{C}=\mathrm{C}$ peaks only obviously exist in the sample fabricated by CB washing process. After annealing, samples based on IPA washing and mixed anti-solvent washing don't show any $\mathrm{C}=\mathrm{C}$ peaks of chlorobenzene. This result clearly demonstrates that there is a small amount of residual CB in perovskite films. But if IPA is used in this process, this residual CB could be removed. While the sample prepared with $\mathrm{CB}$ shows strong $\mathrm{C}=\mathrm{C}$ peaks in the wavenumber between $1650 \mathrm{~nm}^{-1}$ to $1550 \mathrm{~nm}^{-1}$, such peaks becomes weaker when $6 \%$ 
IPA was added into the anti-solvent. Because all the films are not annealed, we believe that the IPA is conducive to quickly remove residual $\mathrm{CB}$ in this washing process. Normally, there is no $\mathrm{C}=\mathrm{C}$ peak in the curve of the sample with pure IPA washing. Confirmed by this result, IPA plays an important role in stitching perovskite films via the mixed anti-solvent process.

The unannealed perovskite films exhibited dramatically different textures as seen by metallographic microscope. (Figure 6 (a)-(d)) Without any anti-solvent treatment, the composite perovskite film shows a colorful surface covered with distributed needlelike crystals indicating a very inhomogeneous nucleation kinetic. After treatment by anti-solvent process (CB, mixed anti-solvent and IPA), radial needle shaped crystals grew in the relative uniform surface having different needle density. With the addition of isopropanol, the distribution of needle crystals is more homogeneous and these radiative crystals become much denser. The differences in crystal size and crystal density further confirm the "stitching effect" of IPA in the mixed anti-solvent. The nucleation kinetics is dominating in this process. [43] This conclusion is also in agreement with the absorption of unannealed perovskite films as shown in Figure S9. The UV-Vis absorption at $\sim 760 \mathrm{~nm}$ of fresh unannealed perovskite films prepared in anti-solvent processes are very high. It reveals that the formation of perovskite had been completed before heating in agreement with the FTIR analysis of the unannealed perovskite films.

We have studied the ratio between DMF and DMSO which act as the solvent of perovskite precursors to improve the performance of our device. The result is shown in 
supporting materials. After optimization, we achieved the best performance device based on mixed solvent $(\mathrm{CB}$ : IPA=1:0.06) process which exhibits a short-circuit current density $\left(\mathrm{J}_{\mathrm{SC}}\right)$ of $24.47 \mathrm{~mA} \mathrm{~cm}^{-2}$, an open-circuit voltage $\left(\mathrm{V}_{\mathrm{OC}}\right)$ of $1130 \mathrm{mV}$, and a FF of 0.694, resulting in a PCE of $19.2 \%$. The $\mathrm{J}-\mathrm{V}$ curve is shown in Figure 7(a). The stability of our device was also considered. Figure 7(b) shows three PCEs were measured at 0 $\mathrm{h}, 12 \mathrm{~h}$ and $36 \mathrm{~h}$ after the fabrication, respectively. The perovskite solar cell shows a good stability. UV-Vis absorption of perovskite films using different anti-solvents after three days of preparation are shown in Figure S10. Each film has a similar high absorption from perovskite at $760 \mathrm{~nm}$ indicating good stability of perovskite. The best PCE was achieved at $12 \mathrm{~h}$ after fabrication and the performance didn't obviously decay for $36 \mathrm{~h}$ after fabrication. Note that, the device was stored in the atmospheric environment of a clean room (in dark, $23-26^{\circ} \mathrm{C}, 40 \%-60 \%$ relative humidity). The EQE and hysteresis analysis are shown in supporting materials. The perovskite with mixed anti-solvent process shows a wide photoresponse from $300 \mathrm{~nm}$ to $800 \mathrm{~nm}$ and the estimated $\mathrm{J}_{\mathrm{SC}}$ value was in good agreement with the $\mathrm{J}_{\mathrm{SC}}$ values from the $\mathrm{J}-\mathrm{V}$ measurement. Meanwhile, the J-V curve of the sample based on mixed anti-solvent process has a slight hysteresis bewteen forward scan mode and reverse scan mode.

\section{Conclusion}

By using solvent-solvent extraction process, different amounts of IPA were added to the anti-solvent. We found that IPA can take away residual CB rapidly in the film, which reduces the density of grain boundaries of perovskite films. Meanwhile, IPA also modifies the surface morphology via its weak solubility of perovskite and perovskite 
precursor. In short, we propose a new "stitching effect" based on the mixed anti-solvent process, which results in a smooth surface morphology of perovskite with large grains. Solar cells fabricated using the anti-solvent process exhibit a best efficiency of $19.2 \%$. This optimized process shows a new way to fabricate high quality perovskite films and high performance solar cells.

\section{Experiment Section}

Materials. $\mathrm{PbI}_{2}, \quad \mathrm{CH}_{3} \mathrm{NH}_{3} \mathrm{I}, \quad \mathrm{FAI}, \mathrm{PbBr}_{2}, \quad \mathrm{CsI}, \quad$ titanium diisopropoxide bis(acetylacetonate) and spiro-OMeTAD were purchased from Sigma-Aldrich. Titanium dioxide nanoparticles (20nm particle size) and solvents, 2-Propanol (IPA, 99. 5\%) and DMF, DMSO, and acetone, were provided by Dyesol and YouXuan respectively.

Device Fabrication. FTO glass substrates were cleaned sequentially in alkaline detergent, acetone, ethanol, and DI water for 15 minutes each, followed by drying with $\mathrm{N}_{2}$ flow. A compact layer of $\mathrm{TiO}_{2}$ was deposited via spray pyrolysis at $500^{\circ} \mathrm{C}$ from a precursor solution of titanium diisopropoxide bis (acetylacetonate) in ethanol (volume ratio 1:39). The films were annealed at $500^{\circ} \mathrm{C}$ for 20 minutes and then cooled down to room temperature. The mesoporous $\mathrm{TiO}_{2}$ scaffold was spin-coated at $4000 \mathrm{rpm}$ for 30s and annealed at $500^{\circ} \mathrm{C}$ for 20 minutes, in which the pristine paste was diluted in ethanol (weight ratio, 1:5). $\mathrm{Cs}_{5} \mathrm{FA}_{79} \mathrm{MA}_{16} \mathrm{PbI}_{2.5} \mathrm{Br}_{0.5}$ was synthesized using the one-step spin coating method and the following experiments except for gold deposition were carried out in a glove box in nitrogen. The perovskite solution contains $517 \mathrm{mg} \mathrm{PbI}_{2}, 171 \mathrm{mg}$

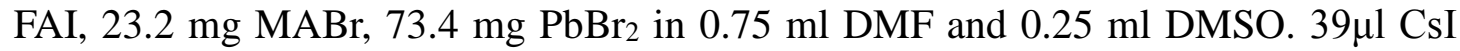


solution (390 mg/ $\mathrm{ml}$ in DMSO) was added into this perovskite solution and stirred more than 2 hours. $80 \mu \mathrm{l}$ perovskite solution was spin-coated at $1000 \mathrm{rpm}$ for $10 \mathrm{~s}$ and $5000 \mathrm{rpm}$ for $45 \mathrm{~s}$. The anti-solvent was poured on the samples at the end of 10 seconds. The samples were annealed at $110^{\circ} \mathrm{C}$ for $1 \mathrm{~h}$. The substrates were subsequently covered with a $72.3 \mathrm{mg} / \mathrm{ml}$ solution of spiro-OMeTAD in $1 \mathrm{ml}$ chlorobenzene with $28.8 \mu \mathrm{l}$ of added 4-tert-butylpyridine, $17.5 \mu \mathrm{l}$ of a stock solution of $520 \mathrm{mg} \mathrm{ml}^{-1}$ lithium bis(trifluoromethylsulphonyl)imide in acetonitrile and $29 \mu \mathrm{l}$ of $520 \mathrm{mg} \mathrm{ml}^{-1}$ tris $(2-(1 \mathrm{H}-$ pyrazol-1-yl)-4-tert-butylpyridine) cobalt(III) bis (trifluoromethylsulphonyl) imide in acetonitrile. This solution was spin-coated at $4000 \mathrm{rpm}$ for $30 \mathrm{~s}$. Finally, $80 \mathrm{~nm}$ of a gold film was deposited using thermal evaporation.

\section{Measurement and Characterization}

X-ray diffraction (XRD) diagrams were carried out using a Bede D1 system with

$\mathrm{Cu} \mathrm{K} \alpha$ radiation. Scanning electron microscope (SEM) images were obtained using field emission fitting SEM (FEI-Inspect F50, Holland). The UV-vis absorption spectrum were measured by an ultraviolet-visible (UV-vis) spectrophotometer (Schimadzu UV-3101 PC).Current-voltage measurements were carried out using Keithley 2400 under AM 1.5G illuminations $\left(1000 \mathrm{~W} / \mathrm{m}^{2}\right)$ from a solar simulator (Newport Oriel Solar 3A Class AAA, 64023A). The AM 1.5G sun light $\left(100 \mathrm{~mW} / \mathrm{cm}^{2}\right)$ was calibrated using a standard Si-solar cell (Oriel, VLSI standards). Metallographic microscope images were carried out by MZ5000 (Jiangnan Yongxin). AFM figures were measured using 300HV scanning force microscope (SEIKO). Steady PL curves were measured by F-4600 Fluorescence 
Spectrophotometer (HITACHI). FTIR iS50R was used to measure our Fourier transform infrared (FTIR) spectroscopies.

\section{Acknowledgement}

This work was supported by the National Natural Science Foundation of China under grant nos. 61421002, 61574029, and 61371046. This work was also partially supported by University of Kentucky.

\section{Reference}

[1] A. Kojima, K. Teshima, Y. Shirai, T. Miyasaka, Journal of the American Chemical Society, 131 (2009) 6050-6051.

[2] W.S. Yang, B.-W. Park, E.H. Jung, N.J. Jeon, Y.C. Kim, D.U. Lee, S.S. Shin, J. Seo, E.K. Kim, J.H. Noh, Science, 356 (2017) 1376-1379.

[3] C. Liu, K. Wang, C. Yi, X. Shi, A.W. Smith, X. Gong, A.J. Heeger, Advanced Functional Materials, 26 (2016) 101-110.

[4] H.C. Liao, P. Guo, C.P. Hsu, M. Lin, B. Wang, L. Zeng, W. Huang, C.M.M. Soe, W.F. Su, M.J. Bedzyk, Advanced Energy Materials, 7 (2017).

[5] S. Li, P. Zhang, Y. Wang, H. Sarvari, D. Liu, J. Wu, Y. Yang, Z. Wang, Z. Zhi David Chen, Nano Res, 10 (2016) 1-12.

[6] Y. Wang, S. Li, P. Zhang, D. Liu, X. Gu, H. Sarvari, Z. Ye, J. Wu, Z. Wang, Z.D. Chen, Nanoscale, 8 (2016) 19654-19661.

[7] F.N. Pardo, D. Benetti, H. Zhao, V. Castaño, A. Vomiero, F. Rosei, Journal of Power Sources, 335 (2016) 138-145.

[8] S. Li, P. Zhang, H. Chen, Y. Wang, D. Liu, J. Wu, H. Sarvari, Z.D. Chen, Journal of 
Power Sources, 342 (2017) 990-997.

[9] J. Burschka, N. Pellet, S.-J. Moon, R. Humphry-Baker, P. Gao, M.K. Nazeeruddin,

M. Grätzel, Nature, 499 (2013) 316-319.

[10] D. Liu, S. Li, P. Zhang, Y. Wang, R. Zhang, H. Sarvari, F. Wang, J. Wu, Z. Wang, Z.D. Chen, Nano Energy, 31 (2017) 462-468.

[11] Y. Zhou, M. Celikin, A. Camellini, G. Sirigu, X. Tong, L. Jin, K. Basu, D. Barba, D. Ma, S. Sun, Advanced Energy Materials, (2017).

[12] Y. Li, J.K. Cooper, W. Liu, C.M. Sutter-Fella, M. Amani, J.W. Beeman, A. Javey, J.W. Ager, Y. Liu, F.M. Toma, Nature communications, 7 (2016).

[13] H.C. Liao, T.L.D. Tam, P. Guo, Y. Wu, E.F. Manley, W. Huang, N. Zhou, C.M.M. Soe, B. Wang, M.R. Wasielewski, Advanced Energy Materials, 6 (2016).

[14] W.Q. Wu, F. Huang, D. Chen, Y.B. Cheng, R.A. Caruso, Advanced Functional Materials, 25 (2015) 3264-3272.

[15] S. Xiao, Y. Bai, X. Meng, T. Zhang, H. Chen, X. Zheng, C. Hu, Y. Qu, S. Yang, Advanced Functional Materials, 27 (2017).

[16] D. Zhao, M. Sexton, H.Y. Park, G. Baure, J.C. Nino, F. So, Advanced Energy Materials, 5 (2015).

[17] Z. Xiao, Y. Zhou, H. Hosono, T. Kamiya, Physical Chemistry Chemical Physics, 17 (2015) 18900-18903.

[18] J. Pan, C. Mu, Q. Li, W. Li, D. Ma, D. Xu, Advanced Materials, 28 (2016) 83098314.

[19] H.D. Kim, H. Ohkita, H. Benten, S. Ito, Advanced materials, 28 (2016) 917-922. 
[20] Z. Yang, B. Cai, B. Zhou, T. Yao, W. Yu, S.F. Liu, W.-H. Zhang, C. Li, Nano Energy, 15 (2015) 670-678.

[21] M.I. Dar, M. Abdi - Jalebi, N. Arora, M. Grätzel, M.K. Nazeeruddin, Advanced Energy Materials, 6 (2016).

[22] Z. Xiao, Q. Dong, C. Bi, Y. Shao, Y. Yuan, J. Huang, Advanced Materials, 26 (2014) 6503-6509.

[23] L. Li, Y. Chen, Z. Liu, Q. Chen, X. Wang, H. Zhou, Advanced Materials, 28 (2016) 9862-9868.

[24] X. Sun, C. Zhang, J. Chang, H. Yang, H. Xi, G. Lu, D. Chen, Z. Lin, X. Lu, J. Zhang, Nano Energy, 28 (2016) 417-425.

[25] W.-Q. Wu, D. Chen, F. Huang, Y.-B. Cheng, R.A. Caruso, Journal of Materials Chemistry A, 4 (2016) 12463-12470.

[26] N.J. Jeon, J.H. Noh, Y.C. Kim, W.S. Yang, S. Ryu, S.I. Seok, Nature materials, 13 (2014) 897-903.

[27] N. Ahn, D.-Y. Son, I.-H. Jang, S.M. Kang, M. Choi, N.-G. Park, Journal of the American Chemical Society, 137 (2015) 8696-8699.

[28] L. Liu, A. Mei, T. Liu, P. Jiang, Y. Sheng, L. Zhang, H. Han, Journal of the American Chemical Society, 137 (2015) 1790-1793

[29] J. Chang, H. Zhu, J. Xiao, F.H. Isikgor, Z. Lin, Y. Hao, K. Zeng, Q.-H. Xu, J. Ouyang, Journal of Materials Chemistry A, 4 (2016) 7943-7949.

[30] D. Zhao, W. Ke, C.R. Grice, A.J. Cimaroli, X. Tan, M. Yang, R.W. Collins, H. Zhang, K. Zhu, Y. Yan, Nano Energy, 19 (2016) 88-97. 
[31] Z. Li, M. Yang, J.-S. Park, S.-H. Wei, J.J. Berry, K. Zhu, Chemistry of Materials, 28 (2015) 284-292.

[32] J. Ye, L. Zhu, L. Zhou, X. Liu, X. Zhang, H. Zheng, G. Liu, Z. Shao, X. Pan, S. Dai, Solar Energy, 136 (2016) 505-514.

[33] M. Saliba, T. Matsui, J.-Y. Seo, K. Domanski, J.-P. Correa-Baena, M.K. Nazeeruddin, S.M. Zakeeruddin, W. Tress, A. Abate, A. Hagfeldt, Energy \& environmental science, 9 (2016) 1989-1997.

[34] D. Juan, X. Xin, S. Jiang-Jian, L. Dong-Mei, L. Yan-Hong, M. Qing-Bo, C. Qiang, Chinese Physics Letters, 32 (2015) 078401.

[35] J. Chen, Y. Xiong, Y. Rong, A. Mei, Y. Sheng, P. Jiang, Y. Hu, X. Li, H. Han, Nano Energy, 27 (2016) 130-137.

[36] Y. Ogomi, A. Morita, S. Tsukamoto, T. Saitho, Q. Shen, T. Toyoda, K. Yoshino, S.S. Pandey, T. Ma, S. Hayase, The Journal of Physical Chemistry C, 118 (2014) 1665116659.

[37] L. Zuo, Z. Gu, T. Ye, W. Fu, G. Wu, H. Li, H. Chen, Journal of the American Chemical Society, 137 (2015) 2674-2679.

[38] Y.C. Shih, Y.B. Lan, C.S. Li, H.C. Hsieh, L. Wang, C.I. Wu, K.F. Lin, Small, (2017). [39] D. Zheng, W. Huang, P. Fan, Y. Zheng, J. Huang, J. Yu, ACS applied materials \& interfaces, 9 (2017) 4898-4907.

[40] H. Fan, W. Shi, X. Yu, J. Yu, Synthetic Metals, 211 (2016) 161-166.

[41] H. Wang, Y. Zheng, L. Zhang, J. Yu, Solar Energy Materials and Solar Cells, 128 (2014) 215-220. 
[42] T. Yamanaka, K. Masumori, R. Ishikawa, K. Ueno, H. Shirai, (2016).

[43] S. Paek, P. Schouwink, E.N. Athanasopoulou, K. Cho, G. Grancini, Y. Lee, Y. Zhang, F. Stellacci, M.K. Nazeeruddin, P. Gao, Chemistry of Materials, 29 (2017) 34903498.

\section{Figure1}

(a)

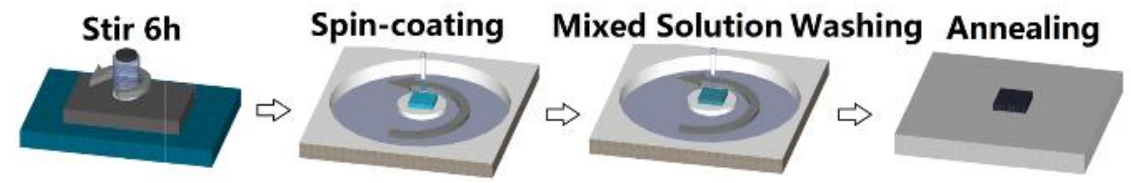

(b)

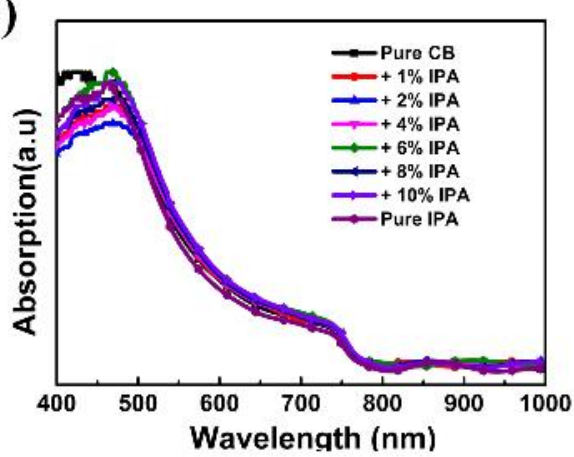

(d)

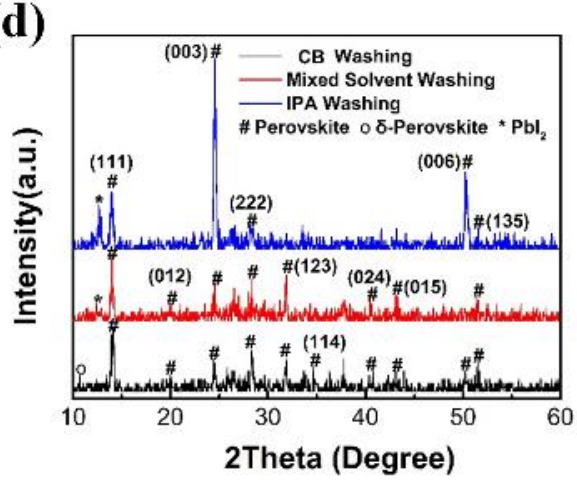

(c)

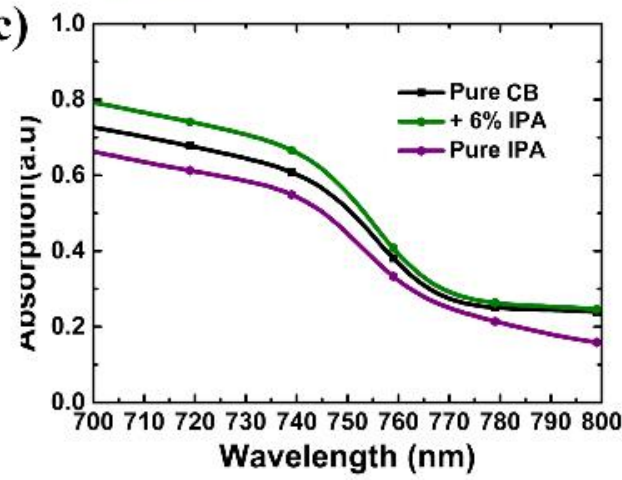

(e)

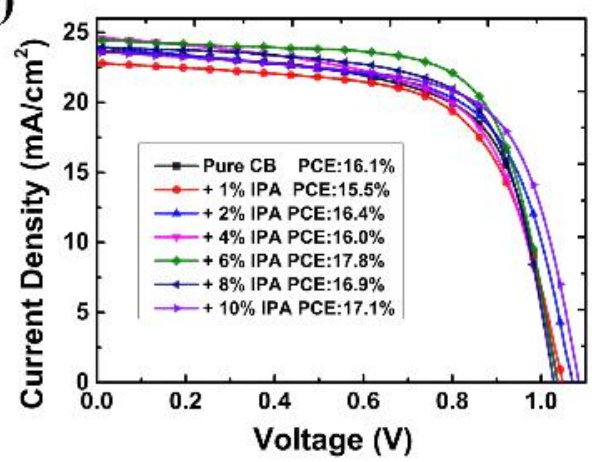

Figure1: (a) The schematic diagram of fabrication methods for PSCs; (b) UV-vis absorption spectra of perovskite using different anti-solvent $(\mathrm{CB}$ : IPA= 1:0, 1:0.01, 1:0.02, 1:0.04, 1:0.06, 1:0.08, 1:0.1, respectively) in fabrication (c) UV-vis absorption spectra (range from $700 \mathrm{~nm}$ to $800 \mathrm{~nm}$ ) of perovskite based on pure $\mathrm{CB}$, mixed solvent $(\mathrm{CB}: I P A=1: 0.06)$ and pure IPA washing (d) XRD patterns of perovskite fabricated by 
pure $\mathrm{CB}$, mixed solvent $(\mathrm{CB}: \mathrm{IPA}=1: 0.06)$ and pure IPA washing method. (e) $\mathrm{J}-\mathrm{V}$ curves of the solar cell samples with $\mathrm{CB}$, mixed solvent and IPA washing processes.

\section{Figure2}
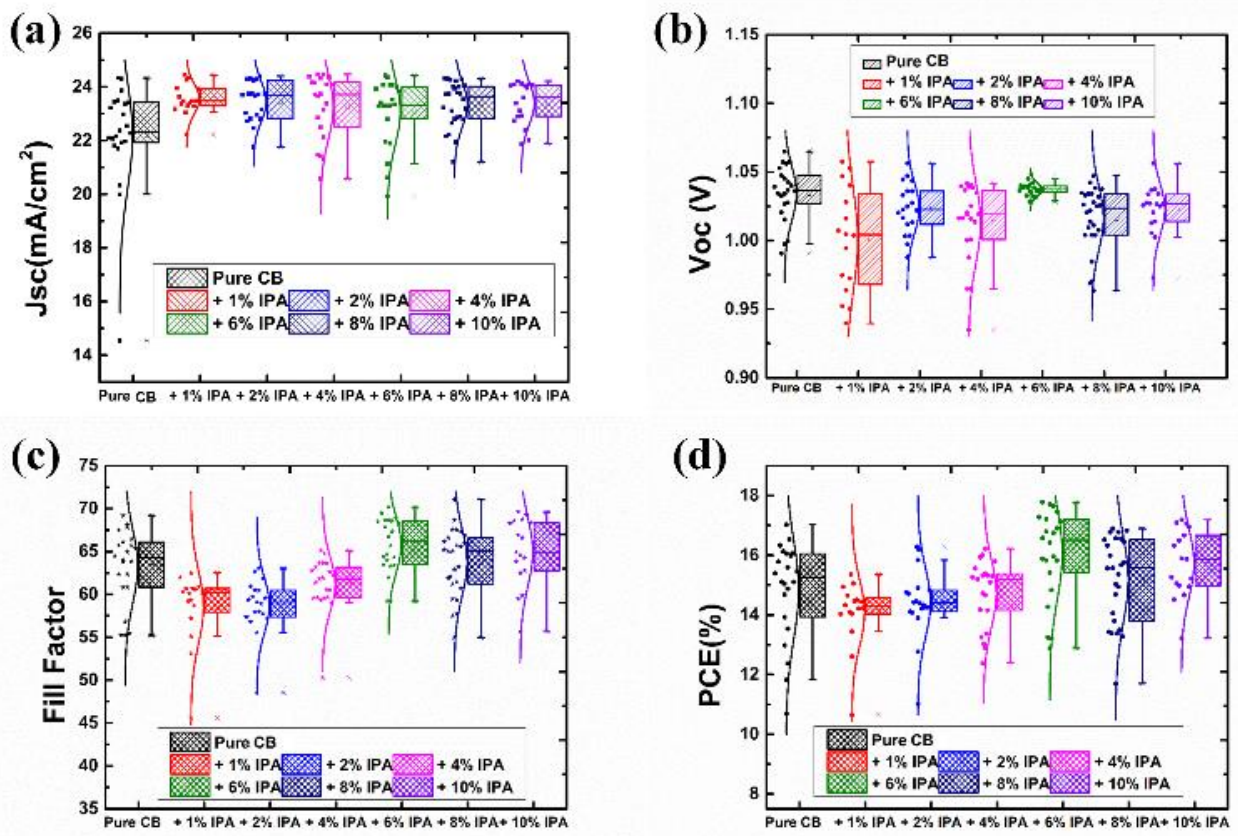

Figure.2 (a)-(d) Distribution of the $\mathrm{J}_{\mathrm{SC}}, \mathrm{V}_{\mathrm{OC}}$, FF and efficiency of the devices with different anti-solvent $(\mathrm{CB}: \mathrm{IPA}=1: 0,1: 0.01,1: 0.02,1: 0.04,1: 0.06,1: 0.08,1: 0.1$, respectively) process.

\section{Figure3}
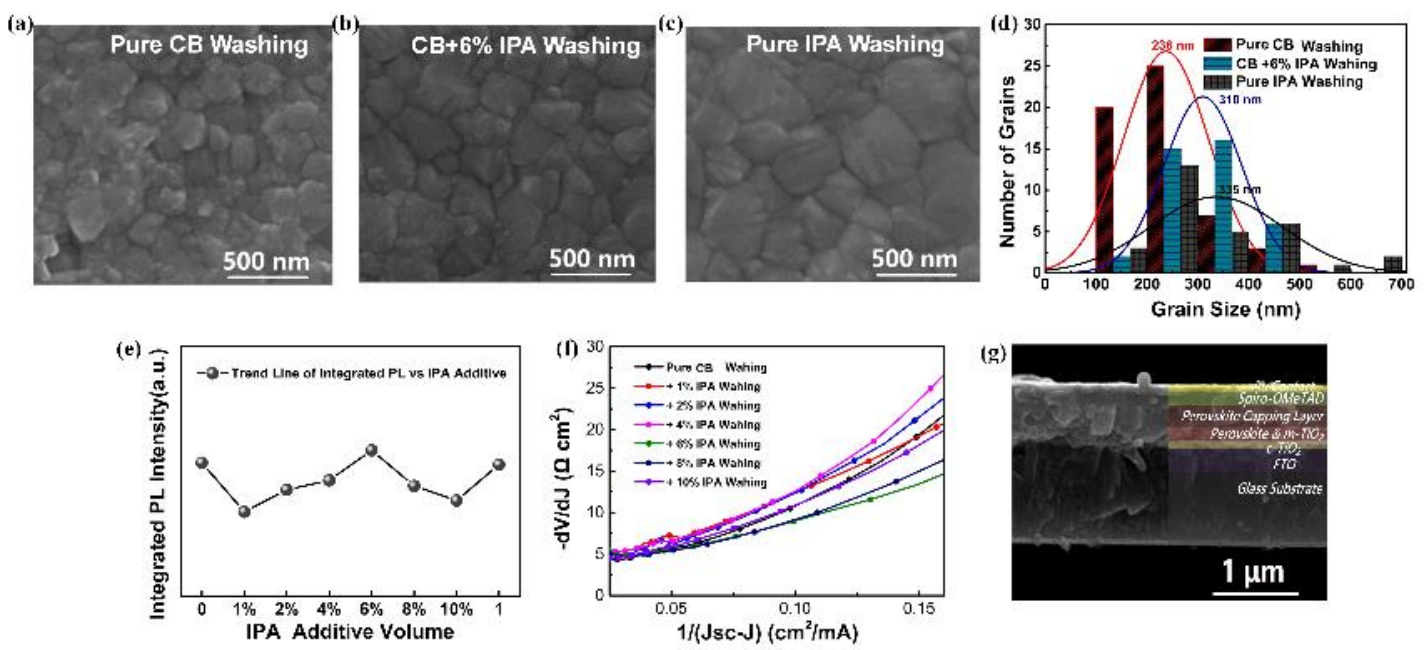
Figure3: (a)-(c) SEM top views of perovskite films treated by pure CB washing, mixed anti-solvent (CB: IPA=1:0.06) and pure IPA washing. (d) Grain size statistics of perovskite films based on $\mathrm{CB}$ washing, mixed anti-solvent (CB: IPA=1:0.06) and pure IPA washing. (e)-(f) Integrated Steady-State PL of perovskite and plots of $-\mathrm{dV} / \mathrm{dJ}$ versus (Jsc-J $)^{-1}$ and the linear fitting curves of PSCs based on different anti-solvent (CB: IPA $=1: 0,1: 0.01,1: 0.02,1: 0.04,1: 0.06,1: 0.08$ and 1:0.1) (g) SEM cross-section image of PSC based on mixed anti-solvent process.

\section{Figure4}
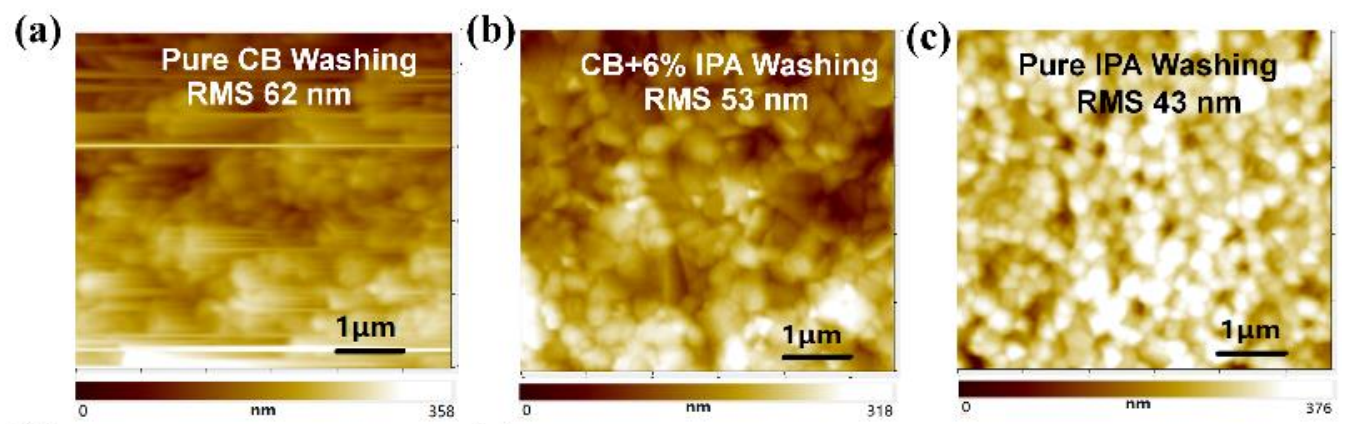

(d)
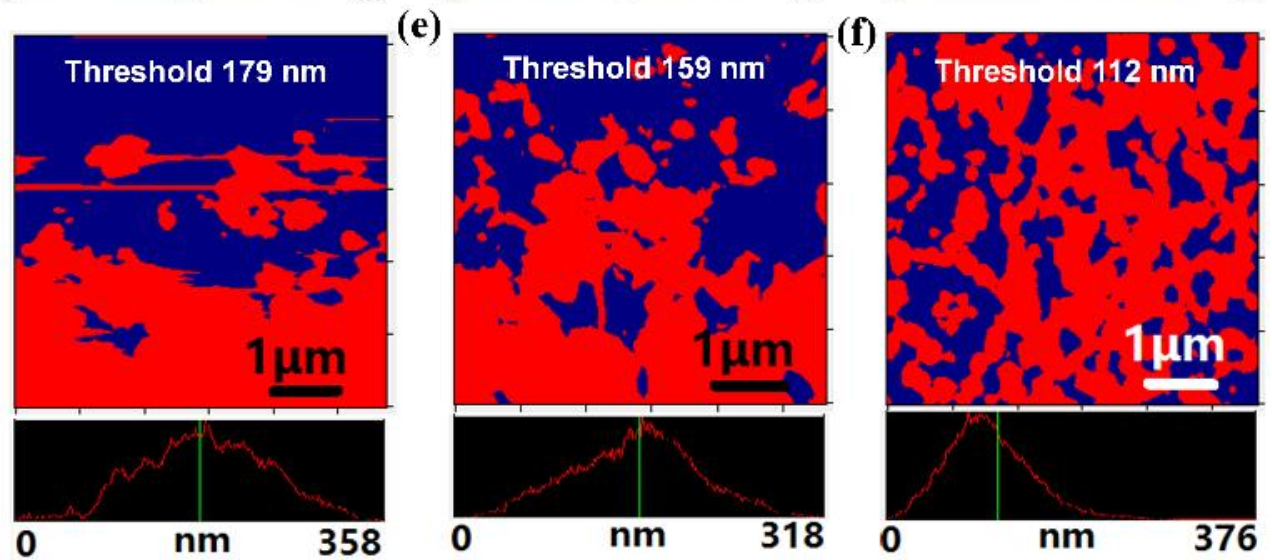

Figure4: (a)-(c) AFM top views of perovskite films and (d)-(f) the height distribution of perovskite films treated by pure $\mathrm{CB}$ washing, mixed anti-solvent $(\mathrm{CB}$ : IPA=1:0.06) and pure IPA washing.

\section{Figure5}



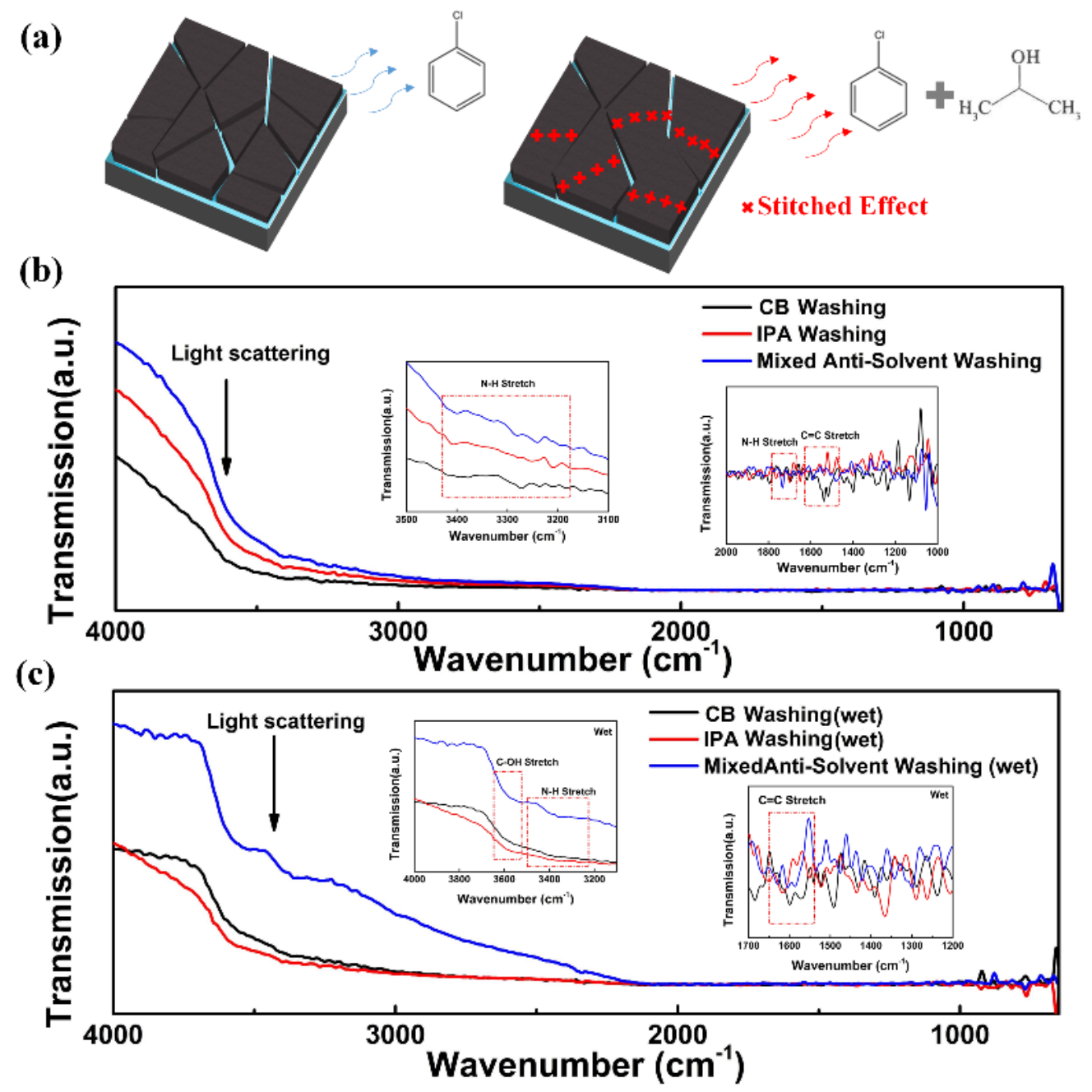

Figure5: (a) The schematic diagram of mixed-anti solvent mechanism. (b)-(c) The FTIR

of annealed and unannealed perovskite films based on CB, IPA and mixed solvent (CB:

$\mathrm{IPA}=1: 0.06)$ washing processes.

\section{Figure6}


(a)

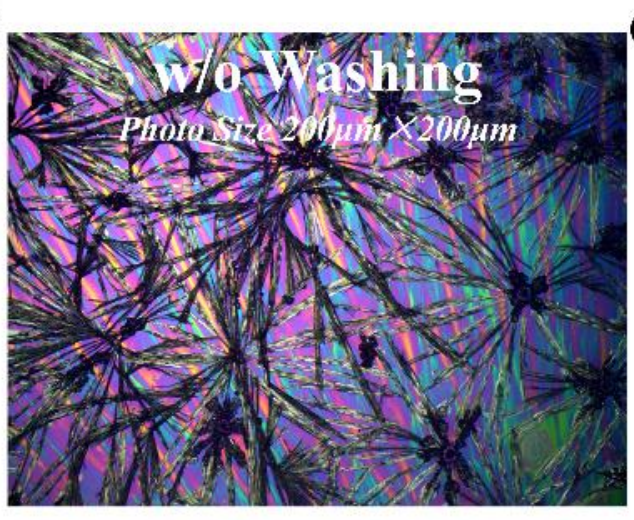

(c)

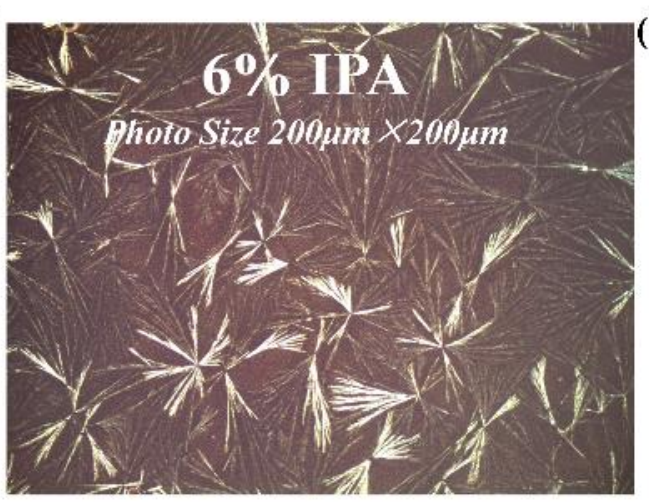

(b)
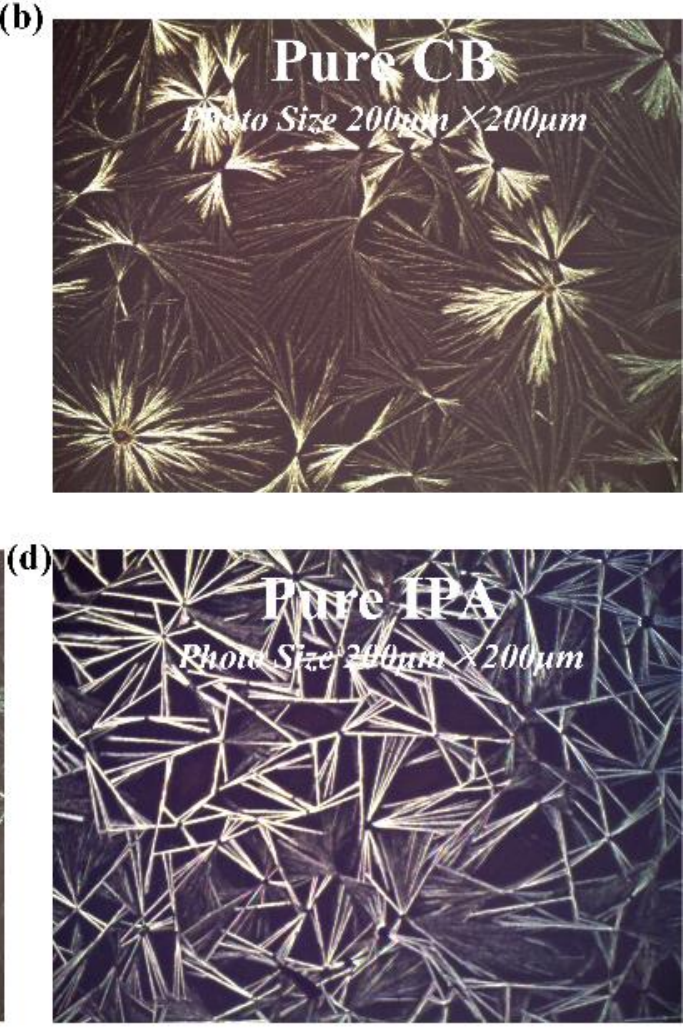

Figure6: (a)-(d) Metallographic microscope images of unannealed perovskite film that is not treated with an anti-solvent process and perovskite films using pure $\mathrm{CB}$, mixed solvent $(\mathrm{CB}: \mathrm{IPA}=1: 0.06)$ and IPA washing processes, respectively.

\section{Figure7}

(a)

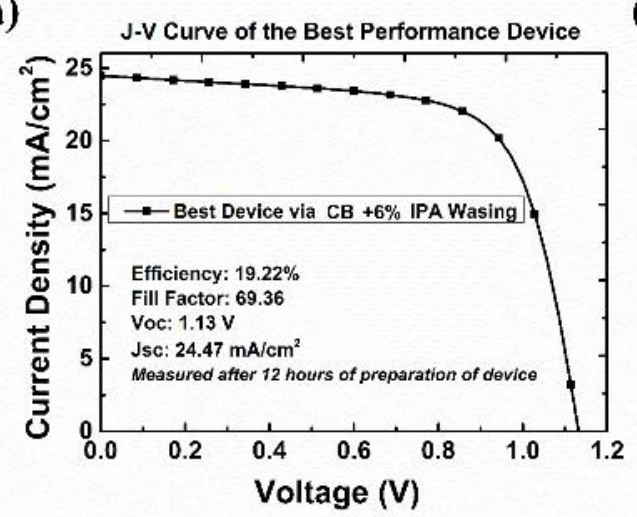

(b)

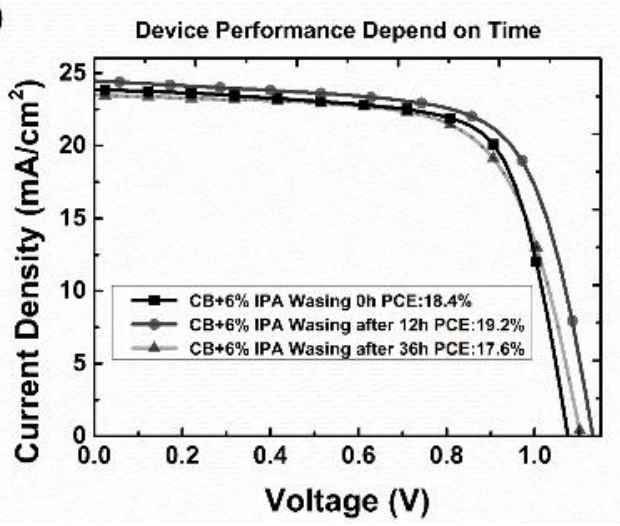

Figure7: (a) J-V curves of the best performance device obtained from mixed antisolvent process; (b) J-V curves of the best performance device obtained from mixed 
anti-solvent process measured at $0 \mathrm{~h}, 12 \mathrm{~h}$ and $36 \mathrm{~h}$ after fabrication.

\section{Supporting Information}

In our study, acetone was also used for "stitching effect". As shown in Figure S1 (a)-(b), J-V curves and statistics of parameters of solar cells based on CB, IPA, CB+6\% IPA and $\mathrm{CB}+3 \%$ acetone anti-solvent processes are exhibited. Compared with pure $\mathrm{CB}$, adding 3\% volume acetone couldn't improve the performance of the solar cell. Acetone could dissolve more perovskite and perovskite precursor that it may seriously rearrange the perovskite film. We also investigate the ratio between DMF and DMSO as the solvent of perovskite to improve the performance of the perovskite solar cell. DMF: $\mathrm{DMSO}=75: 25$ is the best ratio for the deposition of perovskite films in our study. The EQE, integrated current density and its corresponding $\mathrm{J}-\mathrm{V}$ curve are shown in Figure S3 (a)-(b). It is obvious that results of EQE and integrated current density are in good agreement with Jsc from J-V measurement. Figure S4 shows the AFM phase diagrams of perovskite using pure $\mathrm{CB}$, mixed anti-solvent $(\mathrm{CB}+6 \% \mathrm{IPA})$ and pure IPA washing, which are consistent with the previous AFM images. Figure S5 shows photographs of perovskite films based on pure $\mathrm{CB}$, mixed anti-solvent $(\mathrm{CB}+6 \%$ IPA) and pure IPA washing. Metallographic microscope graphs of perovskite films using different ratios between $\mathrm{CB}$ and IPA $(\mathrm{CB}$ : IPA= 1:0, 1:0.01, 1:0.02, 1:0.04, 1:0.06, 1:0.08, 1:0.0 and 0:1) in anti-solvent washing process are exhibited in Figure S7. These measurements of surface morphology demonstrate the different effects on perovskite films through different anti-solvent processes. We also study the hysteresis and find that the J-V curve 
of the sample based on mixed anti-solvent process has a very slight hysteresis contrast to forward scan mode and reverse scan mode as shown in Figure S6. The steady PL intensity spectroscopy shown in Figure S8 display the trend and difference in luminescent intensities of perovskite films fabricated from different mixed anti-solvent $(\mathrm{CB}: \mathrm{IPA}=1: 0,1: 0.01,1: 0.02,1: 0.04,1: 0.06,1: 0.08,1: 0.0$ and 0:1). Figure S9 and S10 shows the UV-Vis absorption of fresh unannealed perovskite films and annealed perovskite films after loading in glove box for about three days.

\section{FigureS1}

(a)

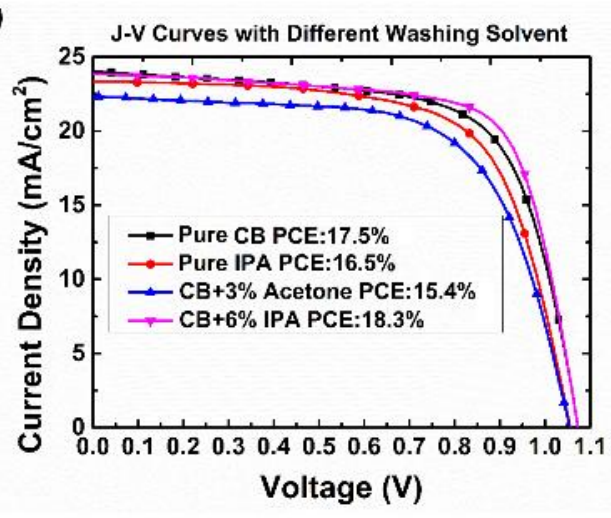

(b)

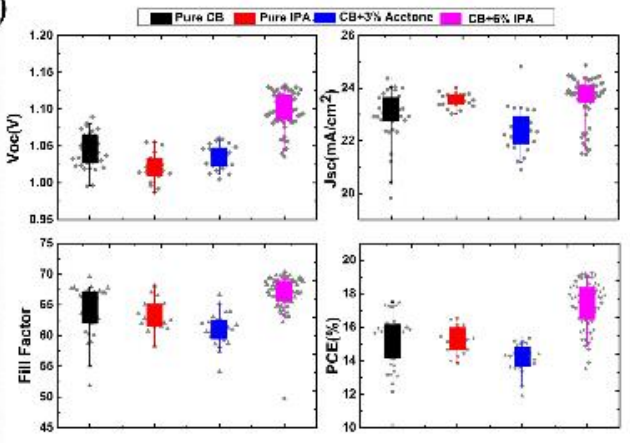

FigureS1: (a)-(b) J-V curves and statistics of $\mathrm{J}_{\mathrm{SC}}, \mathrm{V}_{\mathrm{OC}}, \mathrm{FF}$ and efficiency of the solar cells obtained from pure $\mathrm{CB}$, pure IPA, mixed solvent of $\mathrm{CB}$ and $3 \%$ acetone, and mixed solvent of CB and 6\% IPA anti-solvent process.

\section{FigureS2}




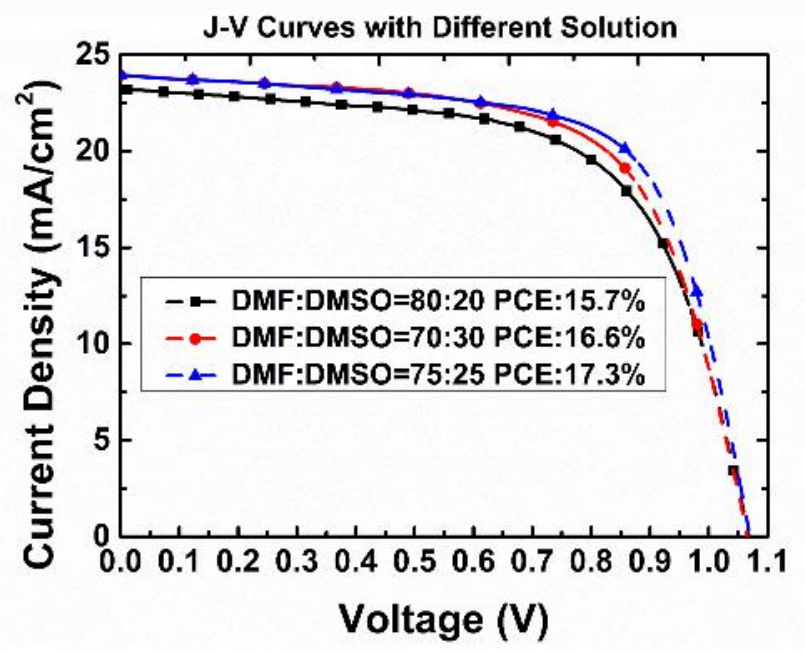

FigureS2: J-V curves of the device using different ratio between DMF and DMSO (80:20, 70:30 and 75:25, respectively) which act as the solvent of perovskite precursor.

FigureS3
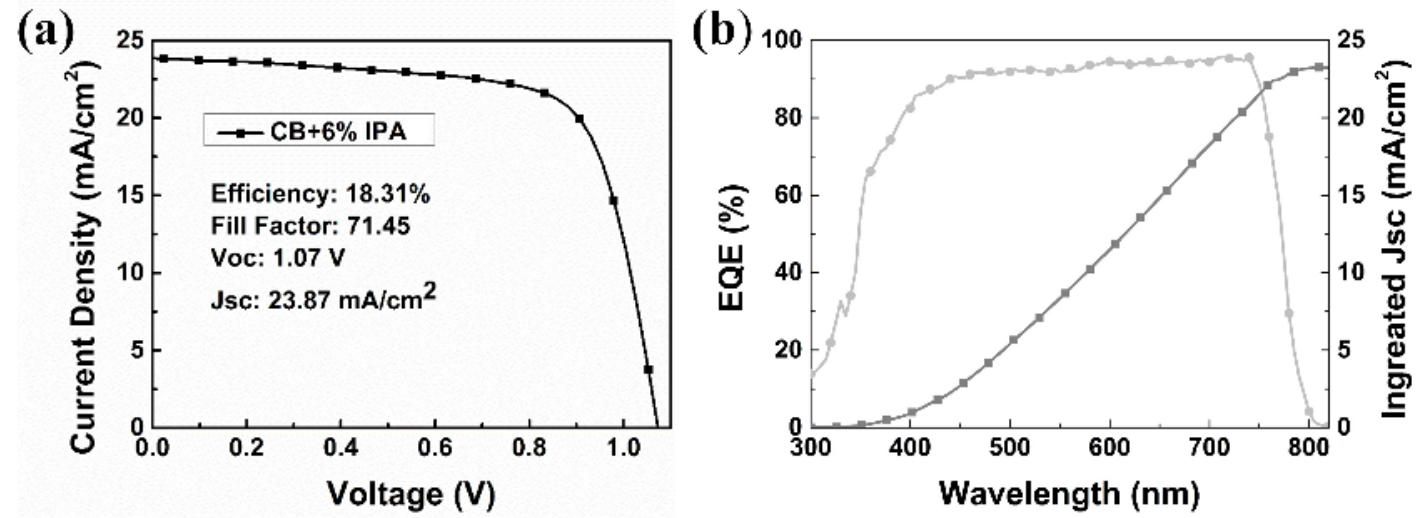

FigureS3: (a)-(b) J-V curve, EQE and integrated current density of the device using mixed anti-solvent $(\mathrm{CB}+6 \% \mathrm{IPA})$.

\section{FigureS4}


(a)

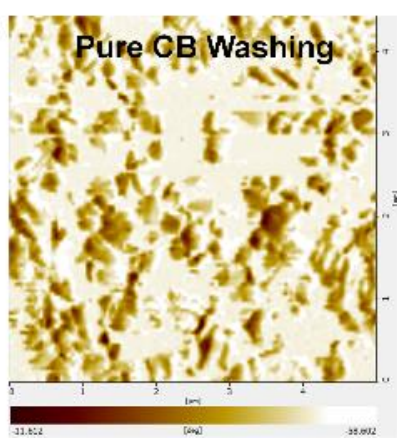

(b)

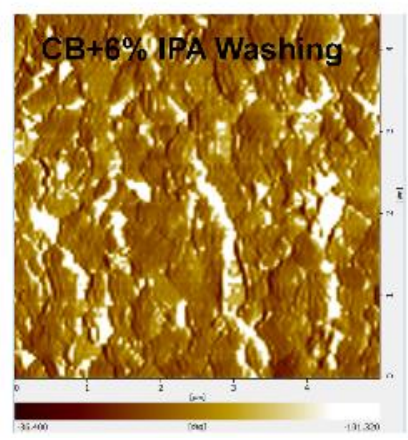

(c)

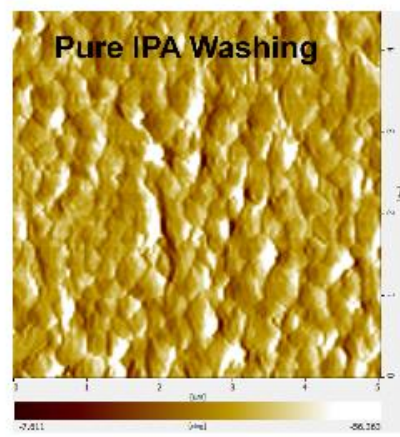

FigureS4: (a)-(c) AFM phase diagrams of perovskite using pure $\mathrm{CB}$, mixed anti-

solvent $(\mathrm{CB}+6 \%$ IPA $)$ and pure IPA washing.

\section{FigureS5}

(a) Pure CB Washing

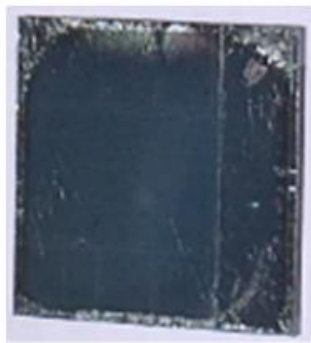

(b) Pure IPA Washing

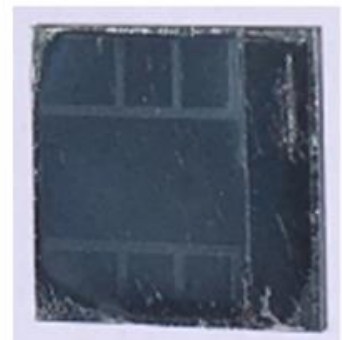

(c) Mixed Solvent Washing
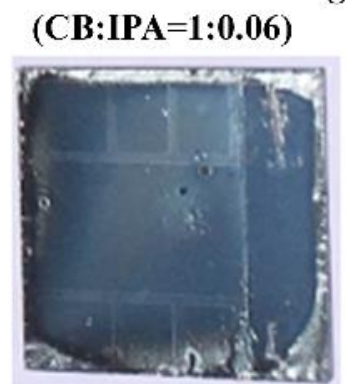

FigureS5: (a)-(c) Photos of perovskite films using pure CB, pure IPA and mixed antisolvent $(\mathrm{CB}+6 \% \mathrm{IPA})$ washing.

\section{FigureS6}

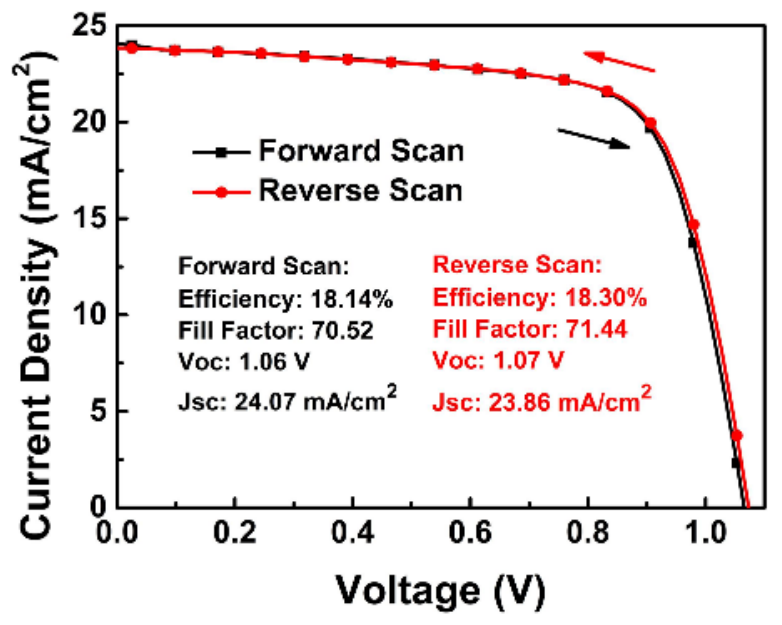

FigureS6: J-V curves (forward and reverse scan) of triple cations perovskite sola cell 
using mixed anti-solvent (CB+6\% IPA) washing process.

\section{FigureS7}

(a)

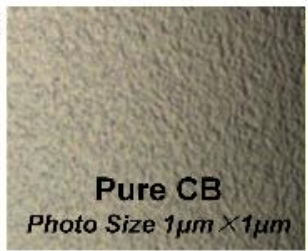

(e)

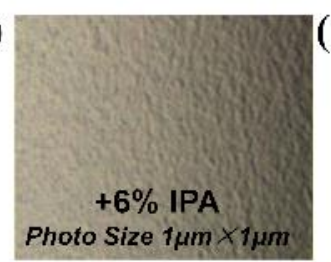

(b)

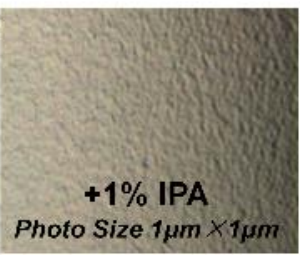

(f)

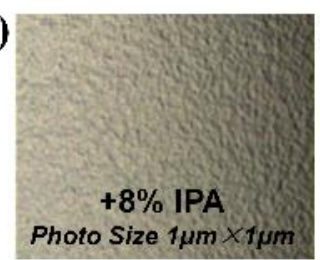

(c)

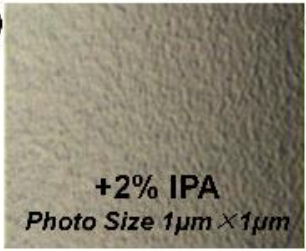

(g)

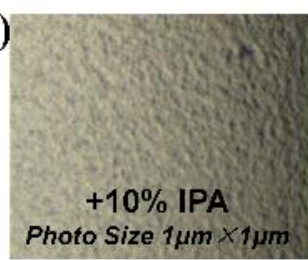

(d)

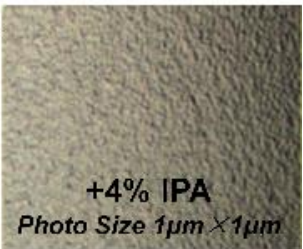

(h)

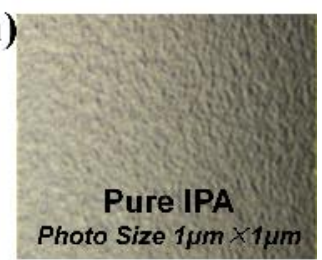

FigureS7: Metallographic microscope graphs of perovskite films using different ratios between CB and IPA (CB: IPA= 1:0, 1:0.01, 1:0.02, 1:0.04, 1:0.06, 1:0.08, 1:0.0 and $0: 1)$ in anti-solvent washing process.

\section{Figure S8}

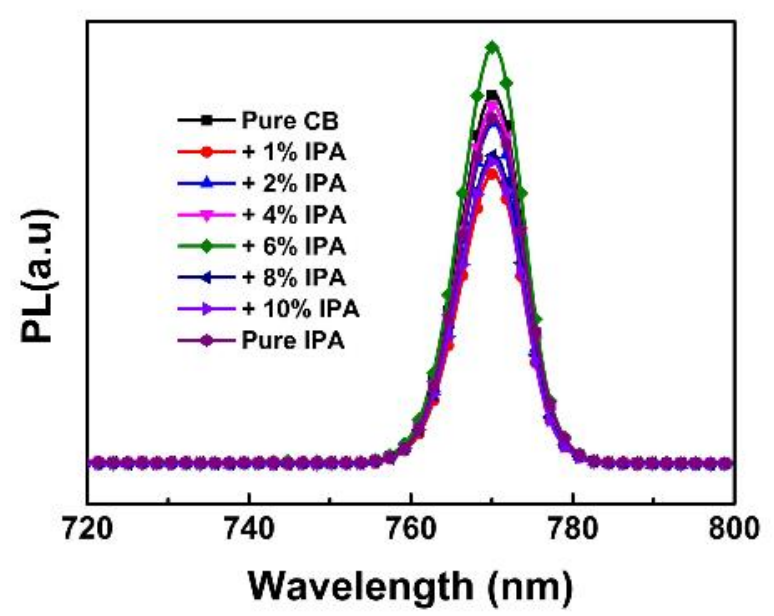

Figure S8: Steady-State PL of perovskite and plots of $-\mathrm{dV} / \mathrm{dJ}$ versus (Jsc-J $)^{-1}$ and the linear fitting curves of PSCs based on different anti-solvent $(\mathrm{CB}$ : IPA= 1:0, 1:0.01, 1:0.02, 1:0.04, 1:0.06, 1:0.08 and 1:0.1)

Figure S9 


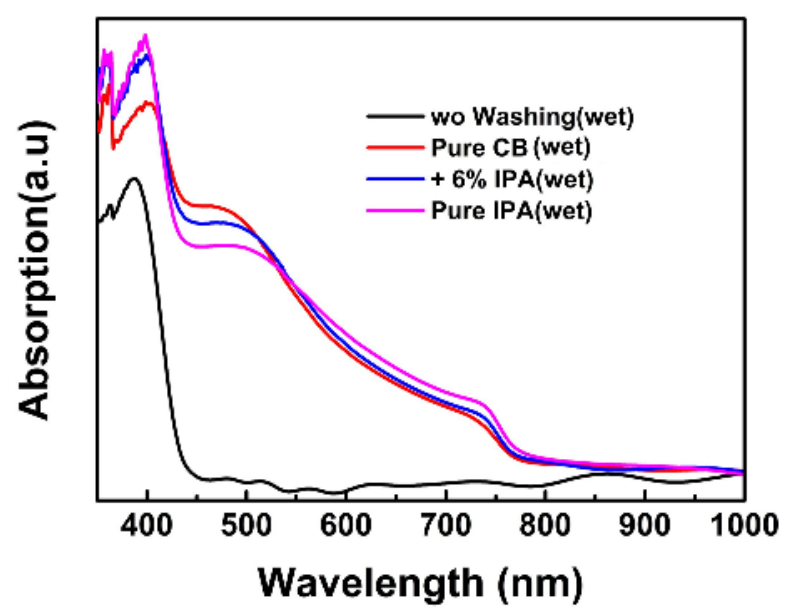

Figure S9: UV-Vis absorption of unannealed perovskite films without anti-solvent process, with $\mathrm{CB}$ washing, mixed solvent washing and IPA washing process, respectively.

\section{Figure S10}

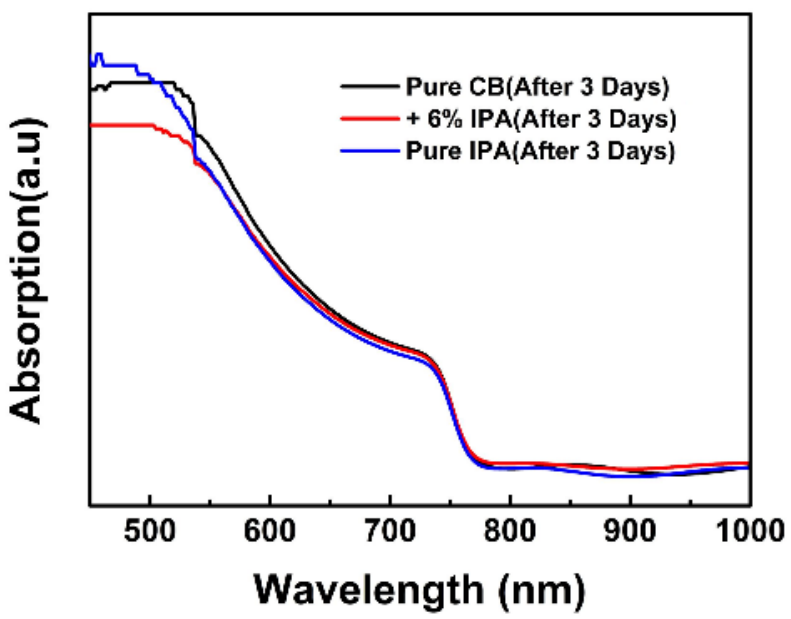

Figure S10: UV-Vis absorption of perovskite films based on $\mathrm{CB}$, mixed anti-solvent and IPA washing on the third days after the preparation.

\section{Figure S11}


(a)

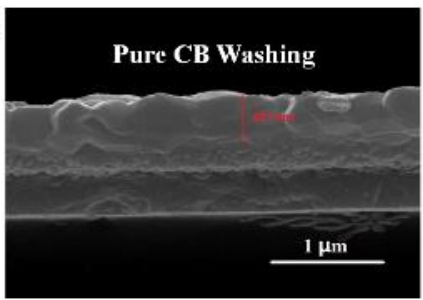

(b)

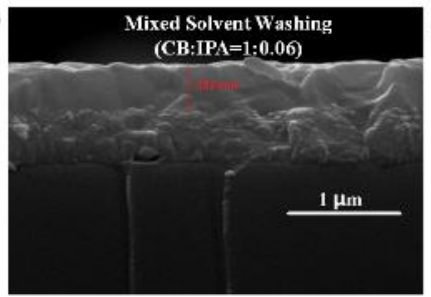

(c)

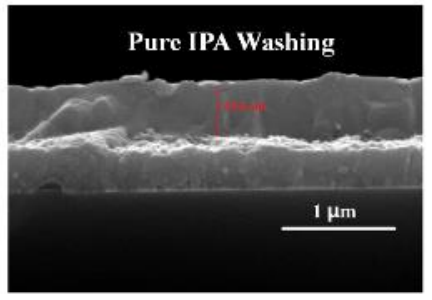

Figure S11: Cross section SEM images of perovskite films based on CB, mixed antisolvent and IPA washing process. 